Original Research Article

\title{
Study of the effect of vildagliptin, a DPP-IV inhibitor on learning and memory dysfunction of diabetic rats
}

\author{
Trupti Rekha Swain*, Manorama Swain, Suchismita Pattnaik
}

\begin{abstract}
Department of Pharmacology, SCB Medical College, Cuttack, Odisha, India
\end{abstract}

Received: 02 April 2017

Accepted: 28 April 2017

*Correspondence to:

Dr. Trupti Rekha Swain,

Email: drtruptiswain@ gmail.com

Copyright: (C) the author(s), publisher and licensee Medip Academy. This is an openaccess article distributed under the terms of the Creative Commons Attribution NonCommercial License, which permits unrestricted noncommercial use, distribution, and reproduction in any medium, provided the original work is properly cited.

\begin{abstract}
Background: To evaluate whether vildagliptin, DPP-IV inhibitor possess a favorable effect on learning and memory dysfunction in the management of Diabetes mellitus.

Methods: Forty Albino rats of either sex weighing 100-180g, were divided into 4 groups of 10 animals each. Streptozotocin was used for induction of diabetes in rats. The rats were divided into 4 groups of eight rats in each. Group-1 was taken as control with no further intervention whereas group-2,3,4 were injected $5 \mathrm{mg} / \mathrm{kg}, 10 \mathrm{mg} / \mathrm{kg}, 20 \mathrm{mg} / \mathrm{kg}$ of vildagliptin respectively for a period of 2 months. At the end of first and second month of treatment period, the rats were subjected to Y maze and EPM tests. The data were analyzed statistically using one-way analysis of variance followed by Student's t test for paired analysis.
\end{abstract}

Results: There was significant decrease in no of arm entries and SAP $(p<0.05)$ in group-1 with induced diabetes. In addition, there was slight increase in no of open arm entries with time spent in open arm for the same group. The decrease in no of arm entries and SAP progressively declined and the no of open arm entries with time spent in open arm progressively increased from group-2 to group 4 till the end of $1^{\text {st }}$ month. After 2 nd month there was further decrease in no of arm entries and SAP $(\mathrm{p}<0.05)$ for group-1. There was significant increase in all parameters for rest of the groups after $2^{\text {nd }}$ month as compared to $1^{\text {st }}$ month. The findings clearly infer the potency of vildagliptin in treating diabetes induced learning and memory impairment.

Conclusions: Vildagliptin significantly reduces the incidence of diabetes induced memory impairment and improves learning if continued further.

Keywords: Diabetes, DPP- 4 inhibitors, Learning, Memory

\section{INTRODUCTION}

Diabetes Mellitus Type-2 (Non-insulin Dependent Diabetes Mellitus or Adult Onset Diabetes) is a metabolic disorder characterised by increase in blood glucose in context of insulin resistance and relative insulin deficiency. People affected with diabetes develop impairment of learning and memory as long-term complication due to alteration in brain insulin signalling and inappropriate regulation of metabolism in CNS. ${ }^{1}$ This problem is aggravated by atherosclerotic changes in blood vessels. Amyloid- beta protein (ABP) produced as an oxidative glucose by-product decreases insulin receptors on neuronal dendrites and is considered responsible for impairment of learning and memory. So type-2 diabetes mellitus is a risk factor for developing
Alzheimer's disease. Vildagliptin,an oral hypoglycemic drug of the new DPP-IV inhibitor class of drugs used in management of diabetes mellitus. It inhibits GLP-1 (glucagon like peptide) and GIP (glucose dependent insulinotropic peptide) by DPP-IV and allows them to potentiate secretion of insulin and suppress secretion of glucagon, thus decreasing blood glucose levels. GLP and GIP receptor are expressed in CNS (neocortex, hippocampus, cerebellum etc.). So GLP and GIP protect neurons from death by suppressing pro-apotic protein Bim, stimulates neurite similar to nerve growth factor and enhance exploratory behaviour. ${ }^{2}$ This was further confirmed by an experiment in which after injection of GLP-1 in a transgenic mouse that overexpresses GLP-1 receptors shows enhanced learning of a spatial task 
whereas deletion of GLP-1 receptor induced impairments in memory function and synaptic plasticity. ${ }^{3,4}$

Whether it is true for humans is unknown GLP-1 can reduce levels of $\mathrm{ABP}$ in brain in vivo and protect cultured hippocampal neurons from oxidative insult. So it can decrease risk of Alzheimer's disease. Acting as a neuromodulator GLP-1, GIP can increase hippocampal release, thus increasing synaptic plasticity and protecting long term potentiation (basis of learning and memory). ${ }^{5}$

The above points suggest a possible therapeutic benefit of incretin hormones in impaired cognition associated with diabetes mellitus (type-2). Thus it was felt necessary to explore whether similar benefits might follow clinical use of DPP-IV inhibitors.

So, to test spatial working memory two tests were devised.

\section{Y-maze}

Rodents show a natural tendency to explore their environment. In this a spontaneous alternation test that relies on latent learning process involved during exploration of Y-maze is evaluated. Rodents typically prefer to investigate a new arm of maze rather than returning to arm that was previously visited. Many parts of brain includinghippocampus, septum, basal forebrain, prefrontal cortex is involved in this task.

\section{Elevated Plus Maze (EPM)}

It is a rodent model of anxiety that is used as a general research tool in neurobiological anxiety research. Total number of open arm entries and time spent in open arms are usually employed as measures of general activity.

The present study was designed to investigate the potential of DPP-IV inhibitors on memory dysfunction in diabetic rats. For this we have used albino rats as experimental models as there are published reports of rats being used as animal models for studying memory dysfunction that can be easily housed, handled, fed and their memory can be easily tested.

\section{Aims and objectives}

- To analyse and assess the effect of vildagliptin on learning and memory dysfunction in streptozotocin induced diabetic rats.

- To ascertain the dosage of vildagliptin that would be effective in dealing against memory dysfunction in rats.

- To analyze the degree of memory and cognition dysfunction induced by streptozotocin, a standard model for induction of diabetes mellitus.

\section{METHODS}

The study was conducted in the department of pharmacology, SCB Medical College and Hospital, Cuttack in collaboration with pathologists of the same institution between May-July 2013 after approval from Institutional Animal Ethics Committee. The experiment was henceforth designed in accordance to the following steps.

\section{Animal stock}

Forty Albino rats of either sex weighing 100-180g were used for the present study. All animals were housed in cages and fed standard animal feed. Normal healthy rats were included in the study whereas those considered diseased after examination by the veterinary surgeon were excluded from the experiment. The rats were divided into 4 groups of 10 animals each.

\section{Induction of diabetes mellitus}

In our study, we have selected streptozotocin (STZ) obtained from Streptomyces achromongenes which is well associated with induction of diabetes in rats. 50 $\mathrm{mg} / \mathrm{kg}$ intraperitoneally single dose was given in accordance to study approved by IJPRD (International journal of Pharmaceutical Research and Development). Initial hyperglycemia is observed 1 hour after the STZ injection followed by hypoglycaemia and again a hyperglycemic state at 48 hours, the elevated blood glucose level was observed by 48-72 hrs (peak, effect) and was maintained thereafter.

\section{Blood test}

Blood glucose estimation was done at the end of $48 \mathrm{hrs}$ in central laboratory of this institute. For collection of blood the rats were not restrained and alarmed as little as possible. The rats having blood glucose level above 135 $\mathrm{mg} / \mathrm{dl}$ were included for the present study. Then the rats were divided into 4 groups of eight rats in each group.

At the end of first and second month of treatment period, the rats were subjected to Y maze and EPM tests.

This is a gross test for spatial memory. It tests to see if the mouse remembers the arm it has just explored and will therefore enter one of the other arms of the maze. In Y-maze spontaneous alternation mice are placed in middle of the Y-maze and are allowed to explore freely all three arms for an 8 minute session. The first 3 minutes are for habituation and for the last 5 minutes the entries into are recorded.

The test is based on the natural aversion of mice for open and elevated areas, as well as on their natural spontaneous exploratory behaviour in novel environments. The apparatus consists of open arms and closed arms, crossed in the middle perpendicularly to 
each other, and a central area. Rats are given access to all of the arms and are allowed to move freely between them. A rat is placed in the central area of the maze with its head directed toward a closed arm. The number of entries (an entry is defined as the centre of mass of the rat that enters the arm) into each open arm and the time spent in the open arms are recorded and these measurements serve as an index of memory retained. An anxiogenic drug increases closed arm entries and time spent in closed arms whereas an anxiolytic drug increases open arm entries and time spent in open arms.

Table 1: Plan of study.

\begin{tabular}{|c|c|c|c|}
\hline Groups & No. of rats & Drugs and dose given & Remarks \\
\hline I & 8 & $\begin{array}{l}\text { Streptozotocin dose } 50 \mathrm{mg} / \mathrm{kg} \text { control group for IP once } \\
\text { for induction of Diabetes Mellitus (DM) }\end{array}$ & \\
\hline II & 8 & $\begin{array}{l}\text { Streptozotocin dose } 50 \mathrm{mg} / \mathrm{kg} \\
\text { IP followed by vildagliptin } \\
5 \mathrm{mg} / \mathrm{kg} \text { orally od for } 60 \text { days after induction of diabetes }\end{array}$ & $\begin{array}{l}\text { Effect of } 5 \mathrm{mg} / \mathrm{kg} \\
\text { Vildagliptin on DM-Induced } \\
\text { memory dysfunction }\end{array}$ \\
\hline III & 8 & $\begin{array}{l}\text { Streptozotocin dose } 50 \mathrm{mg} / \mathrm{kg} \\
\text { IP followed by vildagliptin } \\
10 \mathrm{mg} / \mathrm{kg} \text { orally od for } 60 \text { days after induction of diabetes }\end{array}$ & $\begin{array}{l}\text { Effect of } 10 \mathrm{mg} / \mathrm{kg} \\
\text { vildagliptin on DM-induced } \\
\text { memory dysfunction }\end{array}$ \\
\hline IV & 8 & $\begin{array}{l}\text { Streptozotocin dose } 50 \mathrm{mg} / \mathrm{kg} \text { effect of } 20 \mathrm{mg} / \mathrm{kg} \\
\text { IP followed by vildagliptinvildagliptin on } \\
20 \mathrm{mg} / \mathrm{kg} \text { orally od for } 60 \text { days DM-induced memory } \\
\text { after induction of diabetes dys function }\end{array}$ & \\
\hline
\end{tabular}

Evaluation of baseline learning and memory of each rat was observed before starting the experiment. Then the same observation was taken at the end of first and second month of drug therapy.

\section{Statistical analysis}

The data obtained from various study were fit into tabular formats and expressed as mean SEM. They were analyzed statistically using one-way analysis of variance followed by Student's t test for paired analysis. P-values less than 0.05 imply significance.

This study was planned to familiarizing the student with new methods like RAM (Radial Arm Maze) and EPM (Elevated Plus maze).Thus it was felt that the study will throw light on regenerative effects of DPP-IV inhibitor on learning and memory in rodents, that can be implemented for a well-designed clinical study for its future application in human beings for above purpose.

\section{RESULTS}

The four groups of rats were treated with vildagliptin for 60 days and then subjected to Y-maze and EPM tests at the end of $1^{\text {st }}$ and $2^{\text {nd }}$ month.

Evaluation is done on the basis of Spontaneous Alternation Performance (SAP), No of arm entries (NAE) where Alternation behaviour is defined as consecutive entries into each of the three arms without repetition.
$\operatorname{SAP}(\%)=$ No of alternations $\times 100$

Total possible alternations.

$($ Total possible alternations $=$ Total arm entries-2)

Evaluation is based on no of open arm entries (NOAE) and time spent in open arms (TOA).

Table 2: Baseline learning and memory.

\begin{tabular}{|lllll|}
\hline & \multicolumn{2}{l}{ Y-MAZE } & EPM \\
\hline Group & NAE & SAP (\%) & NOAE & TOA (in sec) \\
\hline 1 & 14 & 75 & 7 & 30 \\
\hline 2 & 15 & 76 & 8 & 29 \\
\hline 3 & 14 & 77 & 7 & 30 \\
\hline 4 & 13 & 76 & 8 & 28 \\
\hline
\end{tabular}

Values expressed as mean

Table 2 shows the baseline learning and memory of rats. Baseline No of arm entries in $\mathrm{Y}$ maze ranged from $13.375 \pm 0.512$ to $14.5 \pm 0.835$, SAP in $\mathrm{Y}$ maze ranged from $75 \pm 0.756 \%$ to $76.5 \pm 1.195 \%$, No of open arm entries in EPM ranged from $7.4 \pm 0.518$ to $8.38 \pm 0.518$, Time spent in open arm in EPM ranged from $28.38 \pm 0.916$ s to $29.75 \pm 1.04 \mathrm{~s}$.

Table 3 shows that there was significant decrease in no of arm entries and SAP $(\mathrm{p}<0.05)$ and slight increase in No of open arm entries with time spent in open arm for group-1 as compared to baseline. The decrease in no of 
arm entries and SAP progressively declined and the no of open arm entries with time spent in open arm progressively increased from group-2 to group-4 as compared to baseline.

Table 3: Learning and memory after one month.

\begin{tabular}{|c|c|c|c|c|}
\hline & Y-MAZE & & EPM & \\
\hline Group & NAE & SAP $(\%)$ & NOAE & $\begin{array}{l}\text { TOA (in } \\
\text { sec) }\end{array}$ \\
\hline 1 & $5 \pm 0.756$ & $50.375 \pm 1.19$ & $7.38 \pm 0.92$ & $32.38 \pm 1.41$ \\
\hline 2 & $8.13 \pm 0.84$ & $61.38 \pm 1.06$ & $10.38 \pm 0.92$ & $34.38 \pm 1.6$ \\
\hline 3 & $9 \pm 0.93$ & $64.38 \pm 1.06$ & $11.38 \pm 1.06$ & $35.75 \pm 1.28$ \\
\hline 4 & $11 \pm 0.76$ & $68.38 \pm 1.41$ & $14 \pm 1.07$ & $37.63 \pm 1.41$ \\
\hline
\end{tabular}

Table 4: Learning and memory after two months.

\begin{tabular}{|lllll|}
\hline Group & Y-MAZE & SAP (\%) & NOAE & $\begin{array}{l}\text { TOA (in } \\
\text { sec) }\end{array}$ \\
\hline 1 & $4.13 \pm 0.83$ & $42.125 \pm 1.25$ & $6.25 \pm 0.7$ & $33.38 \pm 1.06$ \\
\hline 2 & $9.13 \pm 1.13$ & $67.38 \pm 0.92$ & $11 \pm 1.31$ & $37.75 \pm 1.49$ \\
\hline 3 & $11.38 \pm 1.06$ & $70.88 \pm 2.03$ & $13.13 \pm 1.126$ & $40.63 \pm 1.41$ \\
\hline 4 & $13.38 \pm 1.41$ & $75.63 \pm 1.06$ & $17.25 \pm 1.28$ & $44.25 \pm 1.28$ \\
\hline
\end{tabular}

Values expressed as mean \pm SEM

It was observed in Table 4 that there was further decrease in in No of arm entries and SAP $(\mathrm{p}<0.05)$ for group- 1 as compared to $1^{\text {st }}$ month. There was significant increase in all parameters for rest of the groups as compared to $1^{\text {st }}$ month.

It was observed that there was significant difference between baseline data and after $1^{\text {st }}$ month data and similarly between $1^{\text {st }}$ month and $2^{\text {nd }}$ month data $(\mathrm{p}<0.05)$ for all groups except in group-1 where baseline and after $1^{\text {st }}$ month TOA (time spent in open arm) data did not show significant difference with $\mathrm{p}=0.351$.

\section{DISCUSSION}

Diabetes Mellitus type-2 is associated with increased rate of cognitive dysfunction i.e. learning and memory impairment. According to NIA (National Institute of Aging) people with diabetes mellitus are at risk for dementia. In diabetes amylin (islet amyloid peptide) secretion increases. This amylin accumulation in brain blood vessels may play a role in amyloid built up and contribute to risk for Alzheimer's disease.

In a research conducted by University Lille Norde, France people with diabetes have shown lower performance in tests of cognitive function especially those testing memory, executive function and psychomotor efficiency by rapid interview and bedside screening tests. Cognitive impairment may have consequences on treatment compliance.DPP-IV inhibitors/gliptins -a new class of oral hypoglycaemic drugs that block DPP-4 and increase GLP and GIP. So used to treat according to research conducted by Pintana et al DPP-IV inhibitor decreases brain dysfunction in high fat diet(HFD)-induced insulin rats. 60 male wister rats were given HFD for 12 weeks and divided into 2 groups-one receiving vildagliptin $(3 \mathrm{mg} / \mathrm{Kg} /$ day $)$ and others receiving sitagliptin $(30 \mathrm{mg} / \mathrm{Kg} /$ day $)$ for 21 days. Cognitive behaviour of rats was tested by Morris water maze. After completion, their brains were investigated. They demonstrated that both drugs decreased circulating and brain oxidative stress levels. Thus preventing brain and hippocampal mitochondrial dysfunction and improving learning behaviours impaired by HFD. ${ }^{6}$

Michael et al conducted test on the impact of long term inhibitors of DPP-IV with sitagliptin on deposition of amyloid- $\beta$ in brain and deficits in memory related behavioural paradigms in a model of Alzheimer's disease. In this mouse were given sitagliptin at 3 doses $(5,10,20 \mathrm{mg} / \mathrm{kg})$ for 12 weeks by gastric lavage. The treatments, counteracted memory impairment in contextual fear conditioning test, increase in brain concentration of GLP-1, produced significant reduction of nitrosative stress and inflammation hallmarks within brain a significant diminution in ultimate number and total area of $\beta$-APP and Amyloid deposits.

All these effects are much more evident for dose of 20 $\mathrm{mg} / \mathrm{Kg}$. So long term inhibition of endogenesus DPP-4 enzyme with sitagliptin can significantly delay some forms of Alzheimer's diseases pathology, including amyloid deposition when administered early in disease course of a transgenic mouse model of Alzheimer's disease. ${ }^{7,8}$ Research has also been conducted on memory enhancement effect of GLP analogues. Research by Tejashree et al evaluated antipsychotic effect of GLP-1 analogue and sitagliptin in Diabetes mellitus type- 2 . While GLP-1 analogue (50 mg/Kg i.p.) significantly attenuated apomorphine induced, cage climbing, sitagliptin failed to elicit such effect. This is the first preclinical evidence for antipsychotic like effect of GLP agonist. ${ }^{9}$

According to research of Roger et al GLP and it's stable analogues have been demonstrated to exert neuroprotective and antiapoptic effects, reduced amyloid$\beta$ plaque accumulation, modulate long term potentiation, synaptic plasticity and promote differentiation of neuronal progenitor cells. In animal models GLP-1 receptor agonist have demonstrated to improve learning and memory. ${ }^{9}$ In a recent research conducted results showed that amyloid- $\beta$ significantly suppressed HFD (high fat diet) induced late L-LTP in hippocampus, GLP did not affect the baseline synaptic transmission, pretreatment with GLP effectively prevented and reversed amyloid- $\beta$ induced deficit of L-LTP, at molecular level GLP reduced elevated levels of mitochondrial reactive oxygen species and restored dys regulated Akt-glycogen synthase kinase.

These observations suggest a possible therapeutic benefit of incretin hormones in impaired cognition of Diabetes 
Mellitus whether similar benefit might follow clinical use of DPP-IV inhibitors remains to be explored.

In diabetes there is decrease in cognition and memory due to altered insulin signalling, atherosclerotic changes in blood vessels and accumulation of amyloid- $\beta$ protein. This was further clarified by research conducted by University Lille Norde,France and also by NIA(National Institute Of Aging). GLP's diverse array of molecular targets affords great potential to vildaglitin as a therapeutic agent for an effective treatment of diabetes induced memory impairment.Further bioassay guided pharmacological studies are required to identify the exact mechanism(s) of action of vildagliptin that account for it's memory protection activity.

Y-maze and elevated plus maze could clearly depict cognitive behaviour of rats. At the end of $1^{\text {st }}$ month there was significant progressive increase in No of arm entries, SAP as compared to group-1 for groups 2-4.

This was further appreciated at the end of two months. Vildagliptin inhibits breakdown of GLP which by modulating hippocampal release, inhibiting accumulation of amyloid- $\beta$ protein exerts beneficial effect which increases after 2 months of treatment and also with dose. This shows dose and duration dependent beneficial effect of vildagliptin. This finding is in agreement with research conducted by Pintana et al in which vildagliptin (3mg/Kg/day) and sitagliptin $(30 \mathrm{mg} / \mathrm{Kg} /$ day) given for 21 days showed decrease in brain and hippocampal dysfunction caused due to high fat diet as tested by Morris water maze and also research conducted by Michael et al in which Sitagliptin at a dose of $20 \mathrm{mg} / \mathrm{kg}$ produced more evident effects on preventing accumulation of amyloid- $\beta$ protein. However our findings suggest that maximum beneficial effect can de observed at the dose of $20 \mathrm{mg} / \mathrm{kg}$ vildagliptin for treatment period of 2 months.

Whereas in the $1^{\text {st }}$ group of diabetic rats having no intervention there was severe decline in No of arm entries, SAP which continued till the end of 2nd month. This was mainly due to accumulation of amyloid- $\beta$ protein as suggested by research conducted by University Lille Norde, France and also by NIA. It was observed that there was significant progressive increase in No of open arm entries, time spent in open arm in EPM for groups 24 at the end of $1^{\text {st }}$ month which became more evident at the end of 2 months while in group-1 not much difference was observed at the end of $1^{\text {st }}$ month and $2^{\text {nd }}$ month compared to baseline.

This suggests the possible anxiolytic effect of vildagliptin which may further potentiate it's beneficial effect on preventing learning and memory impairment. All the above findings suggest that vildagliptin has dose and duration dependent beneficial effect on learning and memory impairment in diabetic rats.

\section{CONCLUSION}

On the basis of the results obtained from the present study, it can be inferred that vildagliptin besides being an oral hypoglycemic, also has role in preventing memory impairment in Diabetes Mellitus. When used for a period of continuous 30 days it can significantly reduce the incidence of diabetes induced memory impairment which was further effective if therapy was continued for further 30 days. A more in-depth study is required with a larger numbers and controls to further explore the changes seen and look into the mechanisms pertaining to the memory preservation activity of Vildagliptin.

\section{ACKNOWLEDGMENTS}

Authors would like to dedicate this work is to Late Dr. Rudraprasanna Barai who provided guidance and support to the project.

\section{Funding: Indian council of Medical Research Conflict of interest: None declared \\ Ethical approval: The study was approved by the Institutional Ethics Committee}

\section{REFERENCES}

1. F. Pasquier Universite Lille-Nord-de-France Diabetes and cognitive impairment: how to evaluate the cognitive status? Diabetes Metab. 2010 Oct;36(3):S100-5.

2. Gault V, Holscher C. GLP-1 agonists facilitate hippocampal LTP and reverse the impairment of LTP induced by beta-amyloid. Eur J Pharmacol. 2008;587:112-7.

3. During MJ, Cao L, Zuzga DS, Francis JS, Fitzsimons $\mathrm{HL}$, Jiao X, et al. Glucagon-like peptide-1 receptor is involved in learning and neuroprotection. Nat Med. 2003;9:1173-9.

4. Abbas T, Faivre E, Ho' 1scher C. Impairment of synaptic plasticity and memory formation in GLP-1 receptor $\mathrm{KO}$ mice. interaction between type 2 diabetes and Alzheimer's disease, Behav Brain Res. 2009 Dec 14;205(1):265-71.

5. Gault VA, Holscher C. Protease-resistant glucosedependent insulinotropic polypeptide agonists facilitate hippocampal LTP and reverse the impairment of LTP induced by beta-amyloid. J Neurophysiol. 2008;99:1590-5. Mer's disease. Behav Brain Res 2009.

6. Pintanaa H, Apaijaia N, Pratchayasakula W, Chattipakorna N, Siriporn C. Chattipakorna B. Chiang Mai University, Chiang Mai, 50200, Thailand DPP-4 inhibitors improve cognition and brain mitochondrial function of insulin resistant rat. $(\mathrm{J}$ Endocrinol JOE-12-0521; 2013.

7. McIntyrea RS, Powellc AM, Kaidanovich- Beiline O, Soczynskac JK, Mohammad A, Woldeyohannesc $\mathrm{HO}$, et al. The neuroprotective effects of GLP-1: possible treatments for cognitive deficits in 
individuals with mood disorders. (Behav Brain Res 2013 Jan 15;237:164-71.

8. D'Amicoa M, Clara Di F, Marfellab R, Abbatecolab AM, Ferraraccioc F, Francesco R, et al. Long-term inhibition of dipeptidyl peptidase-4 in Alzheimer's prone mice. (Exp Gerontol. 2010 Mar;45(3):202-7.

9. Dixit TS, Sharma AN, Lucot JB, Elased KM. Antipsychotic-like effect of GLP-1 agonist liraglutide but not DPP-IV inhibitor sitagliptin in mouse model for psychosis. Physiology and Behavior. 2013;114$115: 38-41$.

Cite this article as: Swain TR, Swain M, Pattnaik S. Study of the effect of vildagliptin, a DPP-IV inhibitor on learning and memory dysfunction of diabetic rats. Int J Basic Clin Pharmacol 2017;6:1461-6. 